\title{
30-Month randomised clinical trial to evaluate the clinical performance of a nanofill and a nanohybrid composite
}

\author{
Ana Karina Maciel de Andrade ${ }^{a}$, Rosângela Marques Duarte ${ }^{a}$, \\ Fábia Danielle Sales Cunha Medeiros e Silva ${ }^{a}$, André Ulisses Dantas Batista ${ }^{a}$, \\ Kenio Costa Lima ${ }^{b}$, Maria Luíza dos Anjos Pontual ${ }^{c}$, \\ Marcos Antonio Japiassú Resende Montes ${ }^{d, *}$ \\ ${ }^{a}$ Department of Restorative Dentistry, Federal University of Paraíba (UFPB), Cidade Universitária, João Pessoa, PB 58059-900, Brazil \\ ${ }^{\mathrm{b}}$ Faculdade de Odontologia, Department of Dentistry, Federal University of Rio Grande do Norte (UFRN), Av. Salgado Filho, \\ 1787 Natal, RN 59056-000, Brazil \\ ${ }^{\mathrm{C}}$ Department of Clinical and Social Dentistry, Federal University of Paraíba (UFPB), Cidade Universitária, João Pessoa, PB 58059-900, Brazil \\ d Faculdade de Odontologia de Pernambuco, UPE, Departamento de Odontologia Restauradora/Materiais Dentários, \\ Av. Gen. Newton Cavalcanti, 1650 Camaragibe, PE 54753-220, Brazil
}

\section{A R T I C L E I N F O}

Article history:

Received 26 August 2010

Received in revised form

14 September 2010

Accepted 25 September 2010

Keywords:

Nanofill composite

Nanohybrid composite

Clinical evaluation

\begin{abstract}
A B S T R A C T
Objective: To evaluate the clinical performance of a nanofill and a nanohybrid composite in restorations in occlusal cavities of posterior teeth in a randomised trial over 30 months. Methods: Forty-one adolescents participated in the study. The teeth were restored with a nanofill (Filtek Z350, 3M ESPE), a nanohybrid (Esthet-X, Dentsply); Filtek Z250 (3M ESPE) was used as a control. After 30 months, the restorations were evaluated in accordance with the US Public Health Service (USPHS) modified criteria. The McNemar and Friedman tests were used for statistical analysis, at a level of significance of $5 \%$.

Results: There were significant differences in the roughness of Filtek Z250 ( $p=0.008)$ and Filtek Z350 ( $p<0.001$ ) when the four time periods (baseline, 6 months, 12 months and 30 months) were compared. There were significant differences in the marginal adaptation of Filtek Z250 ( $p=0.001)$, Filtek Z350 $(p<0.001)$ and Esthet-X $(p=0.011)$. Except for one of each composite restoration, all the modifications ranged from Alpha to Bravo. There were significant differences in the surface roughness $(p=0.005)$ when the three composites were compared after 30 months.

Conclusions: The materials investigated showed acceptable clinical performance after 30 months. Long-term re-evaluations are necessary for a more detailed analysis of these composites (CEP: \#1252).
\end{abstract}

(C) 2010 Elsevier Ltd. All rights reserved.

\section{Introduction}

Aesthetic considerations are playing a greater role in the treatment planning of dental care, even in the restoration of posterior teeth, stimulated by the popularity of aesthetics, patient demands for nonmetallic restorations and the controversy about the systemic and environmental effects of dental amalgam. ${ }^{1,2}$ In addition, the minimally invasive approach is

\footnotetext{
* Corresponding author. Tel.: +55 813184 7667; fax: +55 8131847659.

E-mail address: majrm@uol.com.br (Marcos Antonio Japiassú Resende Montes). 0300-5712/\$ - see front matter (C) 2010 Elsevier Ltd. All rights reserved. doi:10.1016/j.jdent.2010.09.005
} 
increasingly being emphasised in the dental literature. ${ }^{3}$ Those facts have stimulated the development of adhesive techniques. ${ }^{4}$ Adhesive dentistry became possible after the introduction of etching enamel with acid, ${ }^{5}$ the advent of resin composites, ${ }^{6}$ and the formation of the hybrid layer with adhesive systems first described by Nakabayashi et al. ${ }^{7}$

However, many changes have taken place in adhesive systems and restorative materials. One significant change was the introduction of the first restorative nanocomposite resin for dentistry. Nanotechnology, also known as molecular nanotechnology or molecular engineering, is the production of functional materials and structures in the range of $0.1-$ $100 \mathrm{~nm}$ (the nanoscale) by various physical or chemical methods. ${ }^{8}$ Nanocomposites contain a unique combination of two types of nanofillers $(5-75 \mathrm{~nm})$ and nanoclusters. Nanoparticles are discrete non-agglomerated and non-aggregated particles, $20-75 \mathrm{~nm}$ in size. Nanocluster fillers are loosely bound agglomerates of nano-sized particles. The agglomerates act as a single unit enabling high-filler loading and high strength. As a result of the reduced dimensions of the particles and wide size distribution, increased filler load can be achieved, leading to reduction polymerisation shrinkage and increase in the mechanical properties such as tensile strength and compressive strength to fracture. These properties of nanocomposites seem to be equivalent or sometimes even higher than hybrid composites and significantly higher than microfilled composites. As a consequence, manufacturers now recommend the use of nanocomposites for both anterior and posterior restorations. ${ }^{9-12}$

In addition, there are composites on the market that combine nanoparticles with other micrometric particles, and these provide even better performance. These materials are considered the precursors of nanoparticle composites and are sometimes referred to as nanohybrids. ${ }^{9}$

Clinical trials are important to verify the performance of these composites under real conditions of use. This study evaluated the clinical performance of a nanofill, a nanohybrid, and as a control, a conventional microhybrid composite, in restorations in occlusal cavities of posterior teeth over 30 months. The null hypotheses to be tested were (1) there was no difference in the clinical performance amongst the 3 composites after 30 months, and (2) there was no difference in the clinical performance of the composites with the passage of time.

\section{Materials and methods}

This was a clinical study, under a controlled and randomised design and followed the guidelines published by Consolidated Standards of Reporting Trials (CONSORT). ${ }^{13,14}$

This research was approved by the Research Ethics Committee of the Health Science Center (CEP: \#1252) of the Federal University of Paraíba (Brazil). The volunteers and their guardians were consulted to obtain authorisation for their participation in the research, and for the researchers to use the results, by means of signing a Term of Free and Informed Consent. All the volunteers received complete dental treatment at the Integration Clinic of the Federal University of Paraíba.

\subsection{Population and sample}

The patients in this study were selected from amongst students of either gender at public schools in the municipality of João Pessoa, Paraíba (Brazil). Our sample was restricted to students of public schools who live in the suburbs. These patients were adolescents (mean age \pm SD $13.44 \pm 2.22$ years), very often living under insecure conditions as regards an adequate supply of food and often with no suitable guidance from their parents. We opted for this population because it is representative of this region and the inestimable social contribution we would be making, because these patients cannot afford this type of treatment.

According to Martínez-González et al., ${ }^{15}$ a sample size of 30 patients per research treatment is an adequate number to afford levels of variability that enable the pertinent conclusions sought. The numbers of patients were increased by $20 \%$ anticipating likely losses, thus resulting in a final sample size of 41 patients. In agreement with the recommendations by Hickel et al. ${ }^{16}$ there should not be more than one restoration per group per patient, therefore leading to a final sample composed of 123 permanent molars of 41 volunteers, who were divided into 3 groups (Fig. 1).

\subsection{Eligibility criteria, randomisation and blinding}

The inclusion criteria were as follows: the presence of 3 molars requiring replacement of Class I restorations, or with primary caries on the occlusal surface; occlusal contact with the antagonist tooth; patient in good state of general health. ${ }^{16,17}$ The following were excluded from the study: patients with intense bruxism; molars that presented a carious lesion on a surface other than the occlusal surface and in continuity with the occlusal cavity; pulp exposure during caries removal or cavities with imminent risk of pulp exposure; spontaneous pain or sensitivity to percussion.

To ensure randomness, a draw was held using sealed envelopes, to establish in which group a certain tooth was placed:

- Group I: restorative composite Filtek Z250 (3 M ESPE, St. Paul, MN, USA), representing the control.

- Group II: restorative composite Filtek Z350 (3 M ESPE, St. Paul, MN, USA).

- Group III: restorative composite Esthet-X (Dentsply/Caulk, Milford, DE, USA).

The composition of the materials used is shown in Table 1. Neither the patients nor the examiners knew the commercial brand of the composite used in each tooth thus resulting in a double blind study.

\subsection{Clinical procedure}

The detailed clinical procedures began with anamnesis and analysis of facial and oral soft tissues for the purpose of detecting lesions or abnormal alterations in these tissues. All teeth were then examined after prophylaxis with a brush using a low-speed hand-piece, pumice stone and water paste. Caries were diagnosed by means of visual inspection with the 


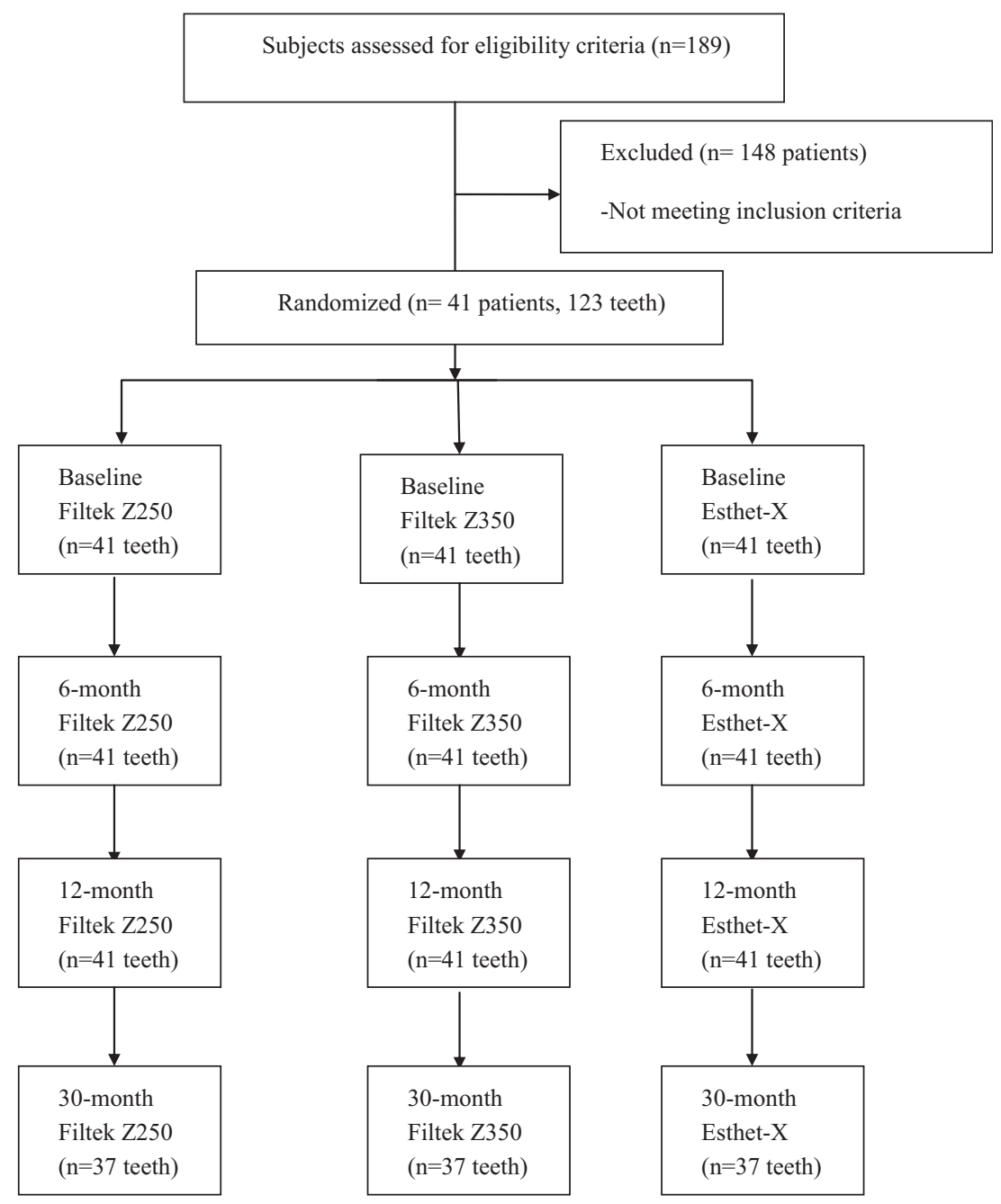

Fig. 1 - Flow-chart of trial.

aid of an oral mirror and a dry, illuminated field. Preoperative radiographs were taken. Periodontal tissues were analysed using a World Health Organization periodontal probe (WHO-621, Trinity, São Paulo, Brazil). The test for pulp thermal sensitivity to cold was performed using a cooling gas (Wilcos do Brasil Ind. e Com. Ltda, Rio de Janeiro, Brazil) under relative isolation, initially in the teeth adjacent and/ or homologous to the tooth in question, and then in the selected tooth.

Articular contacts were initially recorded with Accu Film II articular paper (Parkell, New York, USA). The cavity preparations, with complete isolation of the operating field, were performed with 245 carbide burs (SS White, Rio de Janeiro, Brazil) at high speed, with intermittent movements; removal was limited to carious tissue. Residual caries were removed with a spherical bur at low speed. In cases of unsatisfactory restorations, these and the remaining carious tissues were removed.

In deep cavities, photo-activated glass ionomer cement (Vitrebond; 3M ESPE, St. Paul, MN, USA) was used as a lining, before applying the adhesive system. In shallow and medium cavities, only hybridisation was performed. ${ }^{18}$ The adhesive system, Adper Single Bond 2 (3M ESPE, St. Paul, MN, USA), was applied following the manufacturer's instructions.

The composite was inserted by the incremental technique with a maximum of $2 \mathrm{~mm}$ in each layer, conventional photoactivation with LED light (Optilight LD Max; Gnatus, Ribeirão Preto, São Paulo, Brazil) and irradiance of $600 \mathrm{~mW} / \mathrm{cm}^{2}$ gauged by a radiometer from the same company. The enamel colours were photo-activated for $20 \mathrm{~s}$ each increment, but for darker and more opaque colours, photo-activation was complemented with a further 10-20 s exposure, depending on the manufacturer's recommendations.

After concluding the restoration, occlusion was adjusted with articular paper and a multi-bladed bur (FG7714F, KG Sorensen, Brazil) at high speed. At the following session, final finishing and initial polishing were performed with rubber cups and points (Flexicups and Flexipoints, Cosmedent Inc., Chicago, IL, USA) at low speed. Final polishing was performed using Enamelize paste (Cosmedent Inc., Chicago, IL, USA) and a diamond felt disc (FGM Joinville, Santa Catarina, Brazil) at low speed. 
Table 1 - The commercial brand name, composition and manufacturer of the materials used in the study.

\begin{tabular}{|c|c|c|}
\hline Brand name & Composition & Manufacturer \\
\hline Adper ${ }^{\mathrm{TM}}$ Single Bond 2 & $\begin{array}{l}\text { Primer/adhesive: HEMA, Bis-GMA, dimethacrylates, ethanol, water, photoinitiator } \\
\text { system, functional methacrylate copolymer of polyacrylic and polyalkenoic acids, } \\
\text { and 10\% colloidal silica (size } 5 \mathrm{~nm} \text { ) }\end{array}$ & $\begin{array}{l}\text { 3M ESPE, St. Paul, } \\
\text { MN, USA }\end{array}$ \\
\hline Filtek $^{\mathrm{TM}} \mathrm{Z} 250$ & $\begin{array}{l}\text { Organic matrix: Bis-GMA, UDMA, Bis-EMA } 6 \\
\text { Inorganic particle: zirconium/silica with } 85 \% \text { by weight ( } 60 \% \text { by volume). Size of particles: } \\
0.01-3.5 \mu \mathrm{m} \text { (mean } 0.6 \mu \mathrm{m})\end{array}$ & $\begin{array}{l}\text { 3M ESPE, St. Paul, } \\
\text { MN, USA }\end{array}$ \\
\hline Filtek $^{\mathrm{TM}} \mathrm{Z} 350$ & $\begin{array}{l}\text { Organic matrix: Bis-GMA, UDMA, Bis-EMA } 6 \text {, and small quantities of TEGDMA } \\
\text { Inorganic particle: non-agglomerated nanoparticles of silica with a size of } 20 \mathrm{~nm} \text { and } \\
\text { nanoagglomerates formed of zirconium/silica particles ranging from } 0.6 \text { to } 1.4 \mu \mathrm{m} \\
\text { in size. } 78.5 \% \text { by weight ( } 59.5 \% \text { by volume) }\end{array}$ & $\begin{array}{l}\text { 3M ESPE, St. Paul, } \\
\text { MN, USA }\end{array}$ \\
\hline Esthet-X & $\begin{array}{l}\text { Organic matrix: matrix of urethane modified Bis-GMA, Bis-EMA, and TEGDMA } \\
\text { Inorganic part: vitreous particles of aluminium borosilicate fluoride and silanised barium, } \\
\text { with mean size of less than } 1 \mu \mathrm{m} \text {, colloidal silica } 0.04 \mu \mathrm{m} \text { in size and nanometric silica } \\
77 \% \text { by weight ( } 60 \% \text { by volume) }\end{array}$ & $\begin{array}{l}\text { Dentsply/Caulk, } \\
\text { Milford, DE, USA }\end{array}$ \\
\hline
\end{tabular}

Bis-EMA 6, bisphenol A-polyethylene glycol diether dimethacrylate; Bis-GMA, bisphenol A-diglycidyl ether dimethacrylate; HEMA, 2-hydroxyethyl methacrylate; TEGDMA, triethylene glycol dimethacrylate; UDMA, urethane dimethacrylate.

All the procedures were performed by the same operator, and all the patients received individual oral hygiene instructions and brushes and toothpaste with fluoride.

\subsection{Evaluations}

The restorations were clinically evaluated by two examiners, previously trained and calibrated. Kappa varied from 0.77 to 1 .
When disagreements arose during the evaluations, consensus amongst examiners was obtained. The evaluations were made 1 week after the restorations were performed (baseline), and after 6, 12 and 30 months, in accordance with the criteria (Table 2) established by Dresch et al. ${ }^{19}$ and the website http:// www.dent.umich.edu/cer, ${ }^{20}$ which represents the modified US Public Health Service criteria. Radiographs (bitewings) and periapicals in deep cavities were taken and vitality tests were

\begin{tabular}{|c|c|c|}
\hline Criterion & Code & Definition \\
\hline Anatomic form & $\begin{array}{l}\text { Alpha } \\
\text { Bravo }\end{array}$ & $\begin{array}{l}\text { Restoration continuous with existent anatomic form } \\
\text { Restoration discontinuous with existent anatomic form, but loss of } \\
\text { material is not sufficient to expose the dentin base }\end{array}$ \\
\hline \multirow[t]{3}{*}{ Marginal adaptation } & Alpha & $\begin{array}{l}\text { Restoration completely adapted to the tooth; no visible gap; no explorer } \\
\text { catch at the margins or in any direction }\end{array}$ \\
\hline & Bravo & $\begin{array}{l}\text { Explorer catch; there is no visible evidence of a gap into which the } \\
\text { explorer could penetrate }\end{array}$ \\
\hline & Charlie & Explorer penetrates into a deep gap that exposes dentin or base \\
\hline Marginal discoloration & $\begin{array}{l}\text { Alpha } \\
\text { Bravo } \\
\text { Charlie }\end{array}$ & $\begin{array}{l}\text { No discoloration along the cavo-superficial margin } \\
<50 \% \text { of the cavo-superficial margin affected by stain } \\
>50 \% \text { of the cavo-superficial margin affected by stain }\end{array}$ \\
\hline \multirow[t]{2}{*}{ Colour match } & Alpha & $\begin{array}{l}\text { Restoration with colour and translucency similar to those of the adjacent } \\
\text { dental structure }\end{array}$ \\
\hline & $\begin{array}{l}\text { Bravo } \\
\text { Charlie }\end{array}$ & $\begin{array}{l}\text { Change in colour and translucency within an acceptable standard } \\
\text { Change in colour outside the acceptable standard }\end{array}$ \\
\hline \multirow[t]{2}{*}{ Surface roughness } & $\begin{array}{l}\text { Alpha } \\
\text { Bravo }\end{array}$ & $\begin{array}{l}\text { Restoration surface is smooth } \\
\text { Restoration surface is slightly rough, or has scratches, but can be } \\
\text { refinished }\end{array}$ \\
\hline & Charlie & Surface deeply rough, with irregular scratches; cannot be refinished \\
\hline Secondary caries & $\begin{array}{l}\text { Alpha } \\
\text { Charlie }\end{array}$ & $\begin{array}{l}\text { Absent } \\
\text { Present }\end{array}$ \\
\hline Postoperative sensitivity & $\begin{array}{l}\text { Alpha } \\
\text { Charlie }\end{array}$ & $\begin{array}{l}\text { Absent } \\
\text { Present }\end{array}$ \\
\hline
\end{tabular}


performed. ${ }^{17}$ Post-operative sensitivity was evaluated by questioning the patients and applying an air spray for 3-5 $\mathrm{s}$ from a syringe at a distance of 3-5 $\mathrm{mm}$.

\subsection{Statistical analysis}

The Statistical Package for Social Science (SPSS) was used for the statistical analysis; the McNemar and Friedman nonparametric tests were used at a level of significance of $5 \%$. The McNemar test was applied to verify the homogeneity of the sample and the Friedman test was applied to assess and evaluate differences amongst time-periods for each composite, and differences amongst composites at the end of each time period.

\section{Results}

The characteristics of the samples are shown in Table 3. After performing the statistical tests to verify the homogeneity of the sample, it was found that the distribution of the variables was homogeneous in the three groups $(p>0.05)$. There was no association amongst the variables; that is, the groups were in the same conditions as they were before the restorations were made.

After 30 months, 37 patients were re-evaluated. The results are shown in Table 4 . When the four time periods (baseline, 6 months, 12 months and 30 months) were compared, there were significant differences in the marginal adaptation of Filtek Z250 $(p=0.001)$, Filtek Z350 $(p<0.001)$ and Esthet-X $(p=0.011)$. There were significant differences in the roughness

Table 3 - Sample characteristics.

\begin{tabular}{lcc} 
& $n$ & $\%$ \\
\hline Gender & & \\
$\quad$ Male & 27 & 65.9 \\
$\quad$ Female & 14 & 34.1 \\
Dental element & & \\
$\quad$ Maxillary molar & 43 & 35 \\
$\quad$ Mandibular molar & 80 & 65 \\
Dental condition & & \\
$\quad$ Primary caries & 93 & 75.6 \\
$\quad$ Replacement of restoration & 30 & 24.4 \\
Cavity width & & \\
$\quad$ Larger than 1/3 & 22 & 17.9 \\
$\quad$ Less than 1/3 & 101 & 82.1 \\
Cavity depth & & \\
$\quad$ Shallow & 17 & 13.8 \\
$\quad$ Medium & 76 & 61.8 \\
$\quad$ Deep & 30 & 24.4 \\
Dentin consistency & & \\
$\quad$ Soft & 30 & 24.4 \\
$\quad$ Leathery & 93 & 75.6 \\
Dentin colour & & \\
$\quad$ Yellow & 43 & 35.0 \\
$\quad$ Light brown & 54 & 43.9 \\
$\quad$ Brown & 26 & 21.1 \\
Pulp protection & & \\
$\quad$ Adhesive system & \\
$\quad$ Glass ionomer cement and adhesive system & 30 & 24.4 \\
\hline
\end{tabular}

of Filtek Z250 $(p=0.008)$ and Filtek Z350 $(p<0.001)$. For all of these criteria, there was a decline in the performance of the composite from category Alpha to Bravo, with the exception of one Filtek Z250, one Filtek Z350 and one Esthet-X restoration, which received the score Charlie (clinically unacceptable) for anatomic form, marginal adaptation and recurrent caries (only one Filtek Z350).

There were significant differences in the roughness criteria $(p=0.005)$ when the three composites were compared after 30 months. The roughness of Filtek Z350 was greater, followed by Filtek Z250 and Esthet-X. None of the restorations had postoperative sensitivity.

\section{Discussion}

A nanofill (Filtek Z350) and a nanohybrid composite (Esthet-X) were used in this study; a microhybrid composite (Filtek Z250) was used as the control. These composites are currently available on the market, and their manufacturers present them for restoring anterior and posterior teeth.

Filtek Supreme (3 M ESPE, St. Paul, MN, USA) was the first nanocomposite on the market that contains nanometric particles (nanomers) and nanoclusters (NCs). Nanomers are monodispersed, non-agglomerated, and non-aggregated silica particles of 20 and $75 \mathrm{~nm}$ in diameter. Nanocluster fillers are loosely bound agglomerates of nano-sized particles. On aesthetics, strength and durability, dental nanocomposites show high translucency, high polish and polish retention similar to those of microfilled composites whilst maintaining the physical properties and wear resistance equivalent to those of several hybrid composites. Hence, by virtue of the strength and aesthetic properties of resin-based nanocomposites, clinicians and dental practitioners can use them for both anterior and posterior restorations. ${ }^{8,11,21}$ A few years ago, a new version of this composite, Filtek Supreme XT, was put on the market with major improvements in the shading after feedback on colour matching from opinion leaders and clinicians. $^{22}$ The nanoparticle composite Filtek Supreme XT (3M ESPE) is identical to the Filtek Z350 (3M ESPE) sold in Latin America.

At present, Esthet-X composite is classified as a nanohybrid, because according to Farah and Powers, ${ }^{23}$ materials that combined glass particles, colloidal silica and nano-sized particles should be named nanohybrid composites, not nanofilled composites.

The three types of composites were used in the same patient, for better control of the variables. ${ }^{16}$ As the behaviour of the material was the main objective of this investigation, other variables, such as the type of adhesive system and isolation of the operating field were standardised.

Clinical trials require objective, reliable and relevant criteria to assess the performance of restorations. ${ }^{24}$ The restorations were evaluated by the Modified USPHS criteria, which is a long-established method used in clinical trials. This scoring system was designed to provide comprehensive evidence for acceptance rather than in degrees of clinical success. The restorations were classified as Alpha, Bravo and Charlie. Alpha and Bravo scores mean excellent and clinically acceptable results; a Charlie score means clinically 


\begin{tabular}{|c|c|c|c|c|c|c|c|c|c|c|c|c|c|}
\hline \multirow[t]{2}{*}{ Evaluation criteria } & \multirow[t]{2}{*}{ Score } & \multicolumn{3}{|c|}{ Baseline } & \multicolumn{3}{|c|}{6 months } & \multicolumn{3}{|c|}{12 months } & \multicolumn{3}{|c|}{30 months } \\
\hline & & $\begin{array}{c}\mathrm{Z} 250 \\
(n=41)\end{array}$ & $\begin{array}{c}\text { Z350 } \\
(n=41)\end{array}$ & $\begin{array}{c}\text { Esthet-X } \\
(n=41)\end{array}$ & $\begin{array}{c}\mathrm{Z} 250 \\
(n=41)\end{array}$ & $\begin{array}{c}\text { Z350 } \\
(n=41)\end{array}$ & $\begin{array}{c}\text { Esthet -X } \\
(n=41)\end{array}$ & $\begin{array}{l}\text { Z250 } \\
(n=41)\end{array}$ & $\begin{array}{c}Z 350 \\
(n=41)\end{array}$ & $\begin{array}{c}\text { Esthet-X } \\
(n=41)\end{array}$ & $\begin{array}{c}\mathrm{Z} 250 \\
(n=37)\end{array}$ & $\begin{array}{c}Z 350 \\
(n=37)\end{array}$ & $\begin{array}{c}\text { Esthet-X } \\
(n=37)\end{array}$ \\
\hline \multirow[t]{3}{*}{ Anatomic form } & A & $41(100 \%)$ & $41(100 \%)$ & 41 (100\%) & 40 (97.6\%) & $41(100 \%)$ & 40 (97.6\%) & $40(97.6 \%)$ & 40 (97.6\%) & $40(97.6 \%)$ & $35(94.6 \%)$ & 35 (94.6\%) & 35 (94.6\%) \\
\hline & B & - & - & - & - & - & $1(2.4 \%)$ & - & - & - & $1(2.7 \%)$ & $1(2.7 \%)$ & $1(2.7 \%)$ \\
\hline & C & - & - & - & $1(2.4 \%)$ & - & - & $1(2.4 \%)$ & $1(2.4 \%)$ & $1(2.4 \%)$ & $1(2.7 \%)$ & $1(2.7 \%)$ & $1(2.7 \%)$ \\
\hline \multirow[t]{3}{*}{ Marginal adaptation } & A & $41(100 \%)$ & $41(100 \%)$ & $41(100 \%)$ & 39 (95.1\%) & 40 (97.6\%) & $38(92.7 \%)$ & $31(75.6 \%)$ & $32(78 \%)$ & 35 (85.4\%) & $32(86.5 \%)$ & 29 (78.4\%) & $30(81.1 \%)$ \\
\hline & B & - & - & - & $1(2.4 \%)$ & $1(2.4 \%)$ & $3(7.3 \%)$ & $9(22 \%)$ & 8 (19.5\%) & $5(12.2 \%)$ & $4(10.8 \%)$ & 7 (18.9\%) & $6(16.2 \%)$ \\
\hline & C & - & - & - & $1(2.4 \%)$ & - & - & $1(2.4 \%)$ & $1(2.4 \%)$ & $1(2.4 \%)$ & $1(2.7 \%)$ & $1(2.7 \%)$ & $1(2.7 \%)$ \\
\hline \multirow[t]{3}{*}{ Marginal discoloration } & A & $41(100 \%)$ & 41 (100\%) & 41 (100\%) & 40 (97.6\%) & $41(100 \%)$ & $41(100 \%)$ & $41(100 \%)$ & $41(100 \%)$ & $41(100 \%)$ & $37(100 \%)$ & $36(97.3 \%)$ & $36(97.3 \%)$ \\
\hline & B & - & - & - & $1(2.4 \%)$ & - & - & - & - & - & - & $1(2.7 \%)$ & $1(2.7 \%)$ \\
\hline & C & - & - & - & - & - & - & - & - & - & - & - & - \\
\hline \multirow[t]{3}{*}{ Colour match } & A & 39 (95.1\%) & $38(92.7 \%)$ & 39 (95.1\%) & 37 (90.2\%) & $33(80.5 \%)$ & $37(90.2 \%)$ & 37 (90.2\%) & $33(80.5 \%)$ & 35 (85.4\%) & $32(86.5 \%)$ & $32(86.5 \%)$ & $32(86.5 \%)$ \\
\hline & B & $2(4.9 \%)$ & $3(7.3 \%)$ & $2(4.9 \%)$ & $4(9.8 \%)$ & 8 (19.5\%) & $4(9.8 \%)$ & $4(9.8 \%)$ & 8 (19.5\%) & $6(14.6 \%)$ & $5(13.5 \%)$ & 5 (13.5\%) & $5(13.5 \%)$ \\
\hline & C & - & - & - & - & - & - & - & - & - & - & - & - \\
\hline \multirow[t]{3}{*}{ Surface roughness } & A & $41(100 \%)$ & $41(100 \%)$ & $41(100 \%)$ & $36(87.8 \%)$ & $33(80.5 \%)$ & 38 (92.7\%) & $32(78 \%)$ & $25(61 \%)$ & 37 (90.2\%) & $28(75.7 \%)$ & 22 (59.5\%) & $34(91.9 \%)$ \\
\hline & B & - & - & - & $5(12.2 \%)$ & $8(19.5 \%)$ & $3(7.3 \%)$ & $9(22 \%)$ & $16(39 \%)$ & $4(9.8 \%)$ & $9(24.3 \%)$ & $15(40.5 \%)$ & $3(8.1 \%)$ \\
\hline & C & - & - & - & - & - & - & - & - & - & - & - & - \\
\hline \multirow[t]{2}{*}{ Secondary caries } & A & $41(100 \%)$ & $41(100 \%)$ & $41(100 \%)$ & $41(100 \%)$ & $41(100 \%)$ & $41(100 \%)$ & $41(100 \%)$ & $41(100 \%)$ & $41(100 \%)$ & $37(100 \%)$ & 36 (97.3\%) & $37(100 \%)$ \\
\hline & C & - & - & - & - & - & - & - & - & - & - & $1(2.7 \%)$ & - \\
\hline \multirow[t]{2}{*}{ Postoperative sensitivity } & A & $41(100 \%)$ & $41(100 \%)$ & $41(100 \%)$ & $41(100 \%)$ & $41(100 \%)$ & $41(100 \%)$ & $41(100 \%)$ & $41(100 \%)$ & $41(100 \%)$ & $37(100 \%)$ & $37(100 \%)$ & $37(100 \%)$ \\
\hline & C & - & - & - & - & - & - & - & - & - & - & - & - \\
\hline
\end{tabular}


unacceptable, an indication to replace the restoration to prevent future damage or to repair present damage. ${ }^{21,25}$

The restorations were evaluated for 12 months with the 41 patients involved in the research. However, after 30 months, 4 patients were lost to follow-up because they had moved and could not be located.

There were no differences in anatomic form for the composites evaluated over time and between the composites. Except for one restoration that failed for each composite and one of each composite received a score of Bravo, all the others received the best classification (Alpha) for anatomic form. There was one recurrence of caries and there was no postoperative sensitivity in the patients in this study. There were no differences in marginal discoloration for the composites evaluated over time and between the composites.

After 30 months of clinical use, significant differences were found in the marginal adaptation for each composite over the course of time (baseline, 6 months, 12 months and 30 months). Except for one restoration that failed for each composite, all the other restorations received the classification Alpha (74.8-86.5\%) or Bravo (10.8-19.9\%) for marginal adaptation. Hickel et al. ${ }^{16}$ found that this phenomenon usually appeared within a medium time frame following placement of the restorations. In the study of Palaniappan et al., ${ }^{26}$ within both groups (Z100 and Filtek Supreme), the comparison of restoration performance with time yielded a significant shift of Alpha scores to Bravo indicating a deterioration of marginal adaptation for restorations.

Alteration in marginal adaptation and marginal discoloration over the course of time could also stem from degradation of the resin/bond interface as a result of slow water hydrolysis. Most of the monomers in adhesive materials can absorb water and chemicals from the environment, and this absorbed water weakens the resin/dentin bond over time. Thus, both water sorption and solubility could lead to a variety of chemical and physical processes that may result in deleterious effects on marginal adaptation, discoloration, and colour match of adhesive restorations over time. ${ }^{22,27,28}$ Another possibility associated with a crevice along the marginal interface could be a direct result of a fracture of a slightly overlapping marginal excess. ${ }^{29}$ Shrinkage stress, the effect of cavity geometry on C-factor, buttjoint occlusal margin and self-etch adhesive may also be involved. $^{26}$

The surface roughness of the composites changed over the course of 30 months. Surface roughness changed from Alpha to Bravo over this period; that is, clinically acceptable performance. This difference was found when comparing the 3 composites (Filtek Z350 > Filtek Z250 > Esthet-X), and also for the same composite (Filtek Z350 and Filtek Z250) over the course of time. Our results are supported by the laboratory investigations of Mayworm et al. ${ }^{30}$ who reported that Filtek Supreme has larger particles and/or particle agglomerates and larger inter-particle spacing. Moreover, wear tests caused larger and deeper voids on the Filtek Supreme surface than on the Esthet-X surface, caused by the removal of particles, and possibly of particle agglomerates. However, other clinical trials have shown significantly better or equal polishability for Filtek Supreme compared with microhybrid restorations. ${ }^{26,31,32}$ This divergence of results is not worrisome, because all restorations were classified as clinically acceptable in terms of roughness.
The different results obtained from the trials comparing three types of materials can be explained by the differences in the compositions of the brands, the adhesives used, the physical and chemical properties of the materials tested, and the duration of the clinical studies. Moreover, when performing clinical studies, researchers cannot standardise all the parameters related to their patients. The patient's dental, nutritional, and oral hygiene habits have a great influence on the performance of aesthetic restorations, especially in areas affected by occlusal stresses. ${ }^{22}$

Despite the excellent proposals for nanofill and nanohybrid composites, their clinical performance was not superior to that of the control group, which was restored with Filtek Z250, a microhybrid composite that has been on the dental market for a longer period.The results found after 12 months and 30 months of clinical use were similar; that is, after 1 year only one restoration of each composite was clinically unacceptable and this result was the same after 30 months. This represents stabilisation of the restorations in the oral environment and is indicative of the quality of the restorative composites used in this study.

\section{Conclusions}

The materials investigated showed acceptable clinical performance in Class I restorations after 30 months. Long-term re-evaluations are necessary for a more detailed analysis of these composites. Further long-term clinical trials are necessary to confirm our results.

\section{Acknowledgements}

The authors thank 3M ESPE and Dentsply/Calk for the kind donation of materials for this investigation. The authors do not have any financial interests in the companies whose materials are included in this article.

\section{R E F E R E N C E S}

1. Adabo GL, Cruz CAS, Fonseca RG, Vaz LG. The volumetric fraction of inorganic particles and the flexural strength of composites for posterior teeth. Journal of Dentistry 2003;31:353-9.

2. Brunthaler A, König F, Lucas T, Sperr W, Schedle A. Longevity of direct resin composite restorations in posterior teeth. Clinical Oral Investigations 2003;7:63-70.

3. Efes BG, Dorter C, Gomec Y. Clinical evaluation of an ormocer, a nanofill composite and a hybrid composite at 2 years. American Journal of Dentistry 2006;19:236-40.

4. Loguercio AD, Lorini E, Weiss RV, Torri AP, Picinatto CC, Ribeiro NR, et al. A 12-month clinical evaluation of composite resins in class III restorations. Journal of Adhesive Dentistry 2007;9:57-64.

5. Buonocore MG. A simple method of increasing the adhesion of acrylic filling materials to enamel surfaces. Journal of Dental Research 1955;34:849-53.

6. Bowen RL. Properties of a silica-reinforced polymer for dental restorations. The Journal of the American Dental Association 1963;66:57-64. 
7. Nakabayashi N, Kojima K, Masuhara E. The promotion of adhesion by the infiltration of monomers into tooth substrates. Journal of Biomedical Materials Research 1982;16:265-73.

8. Chen $\mathrm{M}-\mathrm{H}$. Update on dental nanocomposites. Journal of Dental Research 2010;89:549-60.

9. Beun S, Glorieux T, Devaux J, Vreven J, Leloup G. Characterization of nanofilled compared to universal and microfilled composites. Dental Materials 2007;23:51-9.

10. Condon JR, Ferracane JL. Reduced polymerization stress through non-bonded nanofiller particles. Biomaterials 2002;23:3807-15.

11. Mitra SB, Wu D, Holmes BN. An application of nanotechnology in advanced dental materials. The Journal of the American Dental Association 2003;134:1382-90.

12. Yap AUJ, Yap SH, Teo CK, Ng JJ. Comparison of surface finish of new aesthetic restorative materials. Operative Dentistry 2004;29:100-4.

13. Altman DGSK, Moher D, Egger M, David off F, Elbourne D, Gotzsche PC, et al. The revised CONSORT statement for reporting randomized trials: explanation and elaboration. Annals of Internal Medicine 2001;134:663-94.

14. Schulz KF, Altman D, Moher D, for the CONSORT group. CONSORT 2010 statement: updated guidelines for reporting parallel group randomised trials. British Medical Journal (Clinical research ed) 2010;340:698-702.

15. Martínez-González MA, Sánchez-Villegas A, Fajardo JF. Bioestadística Amigable. 3rd ed. España: Ediciones Díaz de Santos; 2009. 919 pp.

16. Hickel R, Roulet JF, Bayne S, Heintze SD, Mjör IA, Peters M, et al. Recommendations for conducting controlled clinical studies of dental restorative materials. Clinical Oral Investigations 2007;11:5-33.

17. Spreafico RC, Krejci I, Dietschi D. Clinical performance and marginal adaptation of class II direct and semidirect composite restorations over 3.5 years in vivo. Journal of Dentistry 2005;33:499-507.

18. De Souza FB, Guimarães RP, Silva CHV. A clinical evaluation of packable and microhybrid resin composite restorations: one-year report. Quintessence International 2005;36:41-8.

19. Dresch W, Volpato S, Gomes JC, Ribeiro NR, Reis A, Loguercio AD. Clinical evaluation of a nanofilled composite in posterior teeth: 12-month results. Operative Dentistry 2006;31:409-17.

20. Clinical Evaluation of Restorations. Clinical evaluation of restorations for teaching and research; 2007. Available from:
http://www.snapdragonmedia.com/projects/UMDental/ CER/ [Accessed 07.07.07].

21. Cetin AR, Unlu N. One-year clinical evaluation of direct nanofilled and indirect composite restorations in posterior teeth. Dental Materials Journal 2009;28:620-6.

22. Türkün LS, Çelik EU. Noncarious class V lesions restored with a polyacid modified resin composite and a nanocomposite: a two-year clinical trial. Journal of Adhesive Dentistry 2008;10:399-405.

23. Farah JM, Powers JW. Layered resin composites. The Dental Advisor 2003;20:749-51.

24. Mahmoud SH, El-Embaby AE, AbdAllah AM, Hamama HH. Two-year clinical evaluation of ormocer, nanohybrid and nanofill composite restorative systems in posterior teeth. Journal of Adhesive Dentistry 2008;10:315-22.

25. Andrade AKM, Duarte RM, Silva FDSCM, Batista AUD, Lima KC, Montes MAJR. Clinical trials with nanoparticle composite in posterior teeth: a systematic literature review. Brazilian Journal of Oral Sciences 2009;8:114-8.

26. Palaniappan S, Bharadwaj D, Mattar DL, Peumans M, Van Meerbeek B, Lambrecht P. Three-year randomized clinical trial to evaluate the clinical performance and wear of a nanocomposite versus a hybrid composite. Dental Materials 2009;25:1302-14.

27. Armstrong SR, Vargas MA, Chung I, Pashley DH, Campbell JA, Laffoon JE, et al. Resin-dentin interfacial ultrastructure and microtensile dentin bond strength after five-year water storage. Operative Dentistry 2004;29:705-12.

28. Hashimoto M, Ohno H, Kaga M, Endo K, Sano H, Oguchi H. In vivo degradation of resin-dentin bonds in humans over 1 to 3 years. Journal of Dental Research 2000;79:1385-91.

29. Türkün LS, Aktener BO. Twenty-four-month clinical evaluation of different posterior composite resin materials. The Journal of the American Dental Association 2001;132:196203.

30. Mayworm CD, Camargo Jr SS, Bastian FL. Influence of artificial saliva on abrasive wear and microhardness of dental composites filled with nanoparticles. Journal of Dentistry 2008;36:703-10.

31. Ernst CP, Brandenbusch M, Meyer G, Canbek K, Gottschalk F, Willershausen B. Two-year clinical performance of a nanofiller vs a fine-particle hybrid resin composite. Clinical Oral Investigations 2006;10:119-25.

32. Efes BG, Dörter C, Gömeç Y. Clinical evaluation of an ormocer, a nanofill composite and a hybrid composite at 2 years. American Journal of Dentistry 2006;19:236-40. 